\title{
Joaquín Lomba Fuentes (1932-2018)
}

El día 5 de marzo fallecía Joaquín Lomba en Palma de Mallorca, ciudad a la que había trasladado su residencia desde su Zaragoza natal y de cuya Universidad era Catedrático Emérito. Dos días antes acababa de cumplir la edad de ochenta y seis años. El día siguiente, 6 de marzo, sin que aún supiéramos de su muerte, aunque sospechábamos que algo le había ocurrido al no responder al teléfono ni él ni su mujer, Pilar Pérez Páramo, SOFIME celebraba su Asamblea anual, la Sociedad de Filosofía Medieval por él fundada.

La formación intelectual de Joaquín fue muy amplia. Como ha señalado Carmen Ruiz-Bravo Villasante, en la nota necrológica que le dedicó en la Sociedad Española de Estudios Árabes, desde su vocación y formación religiosa cristiana, Joaquín fue un gran conocedor de la filosofía. Era Doctor en Filosofía y en Filología Semítica, títulos obtenidos en las Universidades de Madrid y Granada respectivamente. Consolidó su formación de arabista en Poitiers, Rabat y El Cairo, lo que le permitió ser profesor de lengua árabe en la Universidad de Zaragoza. Catedrático de Instituto y después catedrático en la Universidad de Murcia hasta 1979, Joaquín desplegó una gran tarea de investigación y difusión del saber filosófico, especialmente en filosofía antigua pero, sobre todo, en filosofía árabe y judía de la Edad Media, destacando sus conocimientos sobre el mundo judío y árabe de Aragón, del que era uno de sus mejores estudiosos. Sus publicaciones superan los doscientos trabajos, desde el primero, dedicado a Averroes y editado en las Actas de las Reuniones de Aproximación filosófico-científica de Zaragoza, en 1961, hasta el que posiblemente haya sido su último trabajo, «Ibn Paqûda, Figura-Chave do Pensamento Judaico e Universal», publicado en Na Senda da Razão. Filosofia e Ciência no Medioevo Judaico, organizado por Rosalie Helena de Souza Pereira en la Editorial Perspectiva de Sâo Paulo, aparecido en 2016. Sospecho que Joaquín no llegó a ver esta publicación, puesto que el libro lo recibimos en España avanzado ya el año 2017 y una de las últimas veces que hablé con él me dijo que aún no lo había obtenido, quizá por el cambio de domicilio de Zaragoza a Palma de Mallorca. Consagró diversos estudios al polígrafo cordobés del siglo XI, Ibn Hazm, a cuyo pensamiento estético había dedicado su Tesis Doctoral. Entre sus libros hay que destacar los siguientes: El pensamiento de Camón Aznar, Zaragoza, 1984; El oráculo de Narciso. Lectura del poema de Parménides, Zaragoza, 2." edición 1992; Principios de Filosofia del arte griego, Barcelona, 1987; La filosofia islámica en Zaragoza, Zaragoza, 2. a edición, 1991; La filosofia judía en Zaragoza, Zaragoza, 1988; Avempace, Zaragoza, 1989; La corrección de los caracteres de Ibn Gabirol (introducción, traducción y notas), Zaragoza, 1990; Ibn Paqûda. Los deberes de los corazones (Introducción, traducción y notas); Madrid, 1994; Avempace, Madrid, 1995; La raíz semítica de lo europeo, Madrid, 1997; El Régimen del solitario de Avempace (introducción, traducción y notas), Madrid, 1997; Ibn Paqûda, Madrid, 1997; Dichos y narraciones de tres sabios judios. Ibn Gabirol, Ibn Paqûda, Pedro Alfonso, Zaragoza, 1997, bellísimo libro, en el que recoge una colección de textos de tres sabios formados en la cultura judaica, vinculados a Aragón, en el que abundan sentencias que aconsejan conductas prácticas y útiles en este mundo o máximas de contenido religioso y moral; Avempace o la pasión por el espíritu, Madrid, 1999; La felicidad en Aragón musulmán, Zaragoza, 2001; El Ebro: Puente de Europa. Pensamiento musulmán y judio, Zaragoza, 2002; «El mundo tan bello como es». Pensamiento y arte musulmán, Barcelona, 2004; Avempace: La carta del adiós y otros tratados (introducción, traducción y notas), Madrid, 2006; Libro sobre el 
alma (Kitâb al-nafs). Ibn Bayya (Avempace) (introducción, traducción y notas), Madrid, 2007; Avicena esencial. «El Ser Necesario posee la Belleza y el Esplendor puro y es el origen de toda armonía» (introducción y antología), Barcelona, 2009.

Desde 1979 hasta el momento de su jubilación fue Catedrático de Filosofía de la Universidad de Zaragoza, de cuyo Departamento de Filosofía fue Director durante veinte años, desde su incorporación hasta 1997. Ha sido miembro de la Societé Internationale pour l'Étude de la Philosophie Médiévale de Lovaina, de la Societé d'Études Médiévales de Bélgica, de la Societé Internationale d'Histoire de la Philosophie et de la Science Arabes de París, de la Sociedad Internacional Tomás de Aquino y de la Sociedad Española de Estudios Árabes, Ha sido también Miembro de Honor de la Association Tunisienne d'Études Andalouses de Túnez, así como miembro de los Comités Científicos de diversas revistas de su especialidad y del Centro de Estudios Islámicos de Zaragoza. En su actividad investigadora hay que contar su participación en numerosos Congresos y Coloquios celebrados en España, Portugal, Italia, Francia, Alemania, Marruecos, Túnez, Egipto, Siria, Irán, Canadá, Méjico y Argentina, en algunos de los cuales tuve la suerte de acompañarle y ser testigo del gran reconocimiento internacional que Joaquín tenía.

Joaquín era una persona de unas grandes cualidades humanas. Persona afable y cariñosa, generosa y desprendida, siempre receptivo a cualquier idea o sugerencia que se le pudiera hacer, supo recoger una necesidad de la vida intelectual académica española que había estaba inactiva desde hacía años. El 18 de abril de 1962 se había creado en Madrid la Asociación Española de Filosofía Medieval; activa durante años, se disolvió a comienzos de la década de 1980, quizá por el cambio de rumbo que años antes se había dado en la Universidad española. Joaquín, que había pertenecido a ella, quiso recuperar su espíritu y renovarla con un tesón admirable. Por ello, en el otoño de 1989, nos reunió a un grupo de profesores que nos dedicábamos, en mayor o menor medida, al estudio de la Filosofía Medieval, entre los que estaban Vicente Muñoz Delgado, Saturnino Álvarez Turienzo, Josep-Ignasi Saranyana, Horacio Santiago Otero, Mariano Álvarez Gómez, Eudaldo Forment Giralt, María Jesús Lacarra, Jorge Ayala Martínez, Ramón Gabaldós Cardona, de la Editorial Anthropos, y yo mismo. Contamos además con el asesoramiento de D. Antonio Ubieto Arteta, catedrático de Historia Medieval de la Universidad de Zaragoza, reconocido experto en la Edad Media hispana. Su intención era crear una Sociedad que se consagrara al estudio y difusión de la Filosofía Medieval en España. Tras varias sesiones mantenidas en Zaragoza bajo su generoso auspicio, se acordó en la reunión mantenida el día 30 de junio de 1990, erigir la Sociedad de Filosofía Medieval (SOFIME), aprobar un borrador de sus Estatutos y constituir una Junta Directiva Provisional presidida por el Dr. D. Joaquín Lomba Fuentes, actuando como Vicepresidente el Dr. D. Saturnino Álvarez Turienzo y como Secretario el Dr. D. Jorge Ayala Martínez. El objetivo de esta nueva Sociedad era, según el Acta de la reunión, «asociar a todos aquellos profesores e investigadores dedicados a la Filosofía Medieval a fin de colaborar en proyectos comunes de trabajo y de intercambiar investigaciones y publicaciones a la manera como se hace, en concreto, en la Societé Internationale pour l'étude la Philosophie Médiévale». Se acordó igualmente celebrar en Zaragoza los días 12, 13 y 14 del mes de diciembre de 1990 el Primer Congreso de Filosofía Medieval, en el que se realizaría una Asamblea General para aprobar y ratificar los Estatutos provisionales y elegir a la Junta Directiva y cargos correspondientes de una manera definitiva. 
Se celebró el Congreso, consagrado al estudio de «Los límites de la Razón en el pensamiento medieval», con gran asistencia de participantes, se sancionaron los Estatutos y se eligieron por votación los miembros de la Junta Directiva, quedando como Presidente el Dr. Joaquín Lomba Fuentes y como Secretario el Dr. D. Jorge Ayala Martínez. Las Actas del Congreso se publicaron en 1992. A partir de aquí la tarea de Joaquín fue enorme, impulsando todo tipo de proyectos, de tareas y de investigaciones. Convocó dos nuevos Congresos en Zaragoza: el segundo tuvo lugar en diciembre de 1994 y estuvo dedicado a «Ética y política en el pensamiento medieval. Fundamentos de la modernidad» y el tercero se celebró los días 17 y 18 de diciembre, con una asistencia de más de doscientos congresistas, coincidiendo con el Octavo Centenario de la muerte de Averroes, por lo que estuvo dedicado a «Averroes y los averroísmos» y en el que participaron congresistas procedentes de Alemania, Italia, Colombia, Venezuela, Marruecos y Egipto, abierto por tanto ya al ámbito internacional, lo que provocó que poco después se incorporaran a SOFIME tanto Portugal como los países Latinoamericanos. Los tres Congresos contaron con el patrocinio de Ibercaja, la Universidad de Zaragoza, el Gobierno y las Cortes de Aragón. En las Asambleas de SOFIME celebradas con ocasión de estos Congresos, Joaquín fue elegido por unanimidad Presidente de la Sociedad. En el cuarto Congreso, celebrado en Córdoba en diciembre de 2004, que tuvo por objeto principal el octavo centenario de la muerte de Maimónides en 1204, Joaquín puso a disposición de la Asamblea su cargo de Presidente. Se acordó que los próximos Presidentes de SOFIME fueran quienes se encargaran de celebrar el siguiente Congreso y se propuso el nombramiento de Joaquín como Presidente de Honor de la Sociedad.

Además de la Sociedad de Filosofía Medieval, Joaquín promovió la creación de la Revista Española de Filosofia Medieval, queriendo que su director fuera el Profesor Jorge Ayala, que la ha dirigido hasta la actualidad. Su número cero apareció en 1993 y en su presentación Joaquín decía lo siguiente: «No se trata de un hecho puntual y aislado... Llevamos trabajando en esta empresa hace tiempo y la llevamos a efecto ahora... La Revista surge en el marco de un claro movimiento de revitalización de los estudios sobre el pensamiento medieval en nuestro país... Un futuro de la Revista que esperamos que sea largo y profundo». Esta ilusión y este empeño de Joaquín por hacer que la Revista se publicara anualmente se han visto hasta ahora cumplidos. Su deseo era que nuevos investigadores jóvenes se incorporaran a esta tarea; la realidad lo ha confirmado.

Varios homenajes recibió Joaquín en vida con ocasión de su jubilación en la Universidad. En primer lugar el volumen que la Revista Española de Filosofía Medieval le dedicó en el año 2003, titulado Miscellanea Mediaevalia en honor de Joaquín Lomba Fuentes, en el que se publicaron cerca de cuarenta estudios de reconocidos especialistas, divididos en tres apartados: Pensamiento judío, Pensamiento musulmán y Pensamiento cristiano. Un año después aparecía la publicación Las raíces de la cultura europea. Ensayos en homenaje a Joaquín Lomba, editado por la Universidad de Zaragoza y la Institución «Fernando el Católico», también con casi cuarenta estudios divididos en Filosofía antigua, Filosofía y cultura medieval, Filosofía moderna, Filosofía contemporánea, Filosofía del arte y Filosofía moral y política. El volumen se cierra con una semblanza intelectual del Profesor Joaquín Lomba y su obra.

Quienes hemos tenido la suerte de conocer y tratar de cerca a Joaquín, sabemos de la gran persona que se nos ha ido. Gran estudioso, dispuesto siempre a ayudar a quien se lo solicitara, a escuchar y a dirigir, persona afable, bondadosa, sencilla, de un gran rigor intelectual. Había en 
Joaquín un gran entusiasmo por el saber, por conocer nuevas cosas, por investigar, por trabajar, por hacerlo todo con ilusión y con la certeza de que aprender era nuestra tarea vital. Que Joaquín se ocupara en darnos a leer tantos preciosos textos nos muestra mucho de lo que era: el sabio que enseña con la mayor humildad. Que este recuerdo que hacemos aquí de su vida y de su obra sean expresión de nuestra más grande admiración por quien nos contó como compañero y amigo y por quien nos acompañó, junto con su mujer Pilar Pérez Páramo y compartiendo experiencias y anécdotas, en diversos viajes siempre en busca de la sabiduría que él tanto quería y respetaba. Supo encontrar y transmitirnos sapiencia. Por eso, le convienen perfectamente las palabras del Libro de los Proverbios: «Bienaventurado el hombre que encuentra la sabiduría y el que adquiere entendimiento; porque su ganancia es mejor que la ganancia de la plata, y sus utilidades mejor que el oro fino» (Proverbios, 3, 13-14). A Joaquín se le pueden aplicar unas palabras que en otro momento y en otra ocasión escribió nuestro amigo común Alessandro Musco, de la Universidad de Palermo, a quien perdimos hace varios años: «Ha sido fiel, en primer lugar a sí mismo y luego a la vida; ha sido fiel a los valores a los que dedicó su vida de hombre y de investigador; ha sido fiel a sus amigos, a los jóvenes que formó con respeto, cariño y pasión». Quiero acabar con unas palabras que dejó escritas un gran amigo nuestro, que ya nos está esperando allí donde la luz resplandecerá para siempre, Horacio Santiago Otero, quien en la dedicatoria que me hizo al regalarme un libro suyo sobre el Camino de Santiago, me escribió lo siguiente: «Que podamos seguir encontrándonos en el maravilloso Camino de los saberes, de la verdad y del bien». Gracias Joaquín por todo lo que de ti hemos recibido. Descansa en paz, querido amigo y compañero.

RAFAEL RAMÓN GUERRERO

Universidad Complutense de Madrid 